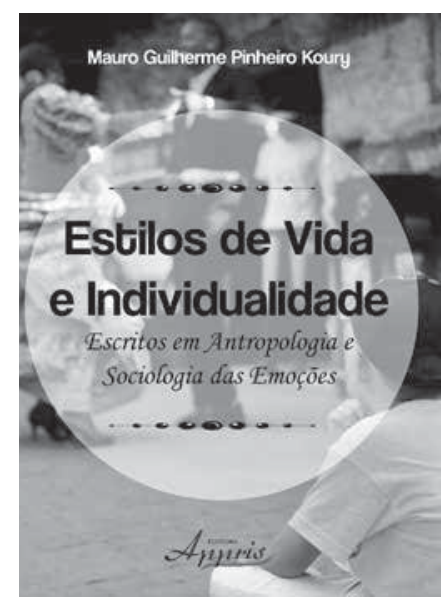

- Estilos de vida e individualidade:

escritos em Antropologia e Sociologia

das emoções

MAURo GuIllerme PINHEIRO Koury, 2014

Appris, Curitiba

\section{Las emociones, los estilos de vida y la individualidad en el Brasil contemporáneo}

\author{
JAINARA GOMES DE OLIVEIRA \\ Y TARSILA CHIARA ALBINO DA SILVA SANTANA
}

Emotions, Lifestyles

and Individuality in

Contemporary Brazil

JAINARA GOMES DE OLIVEIRA

Universidade Federal de Santa Catarina,

Florianópolis, Santa Catarina, Brasil

gomes.jainara@gmail.com

Tarsila Chiara Albino

DA SILVA SANTANA

Universidade Federal do Rio Grande do Norte, Natal, Rio Grande do Norte, Brasil tarsila.chiara@gmail.com

Desacatos 54 , mayo-agosto 2017, pp. 199-203
$C$

Qué son las emociones? ¿Las emociones son biológicas o culturales? ¿Son individuales o sociales? ¿Existen emociones básicas? ¿Hay emociones universales? La colección Estilos de vida e individualidade: escritos em Antropologia e Sociologia das emoções, de Mauro Guilherme Pinheiro Koury, profesor en el Departamento de Ciencias Sociales de la Universidad Federal de Paraíba (UFPB), Brasil, explora el uso de la categoría analítica "emoción" como objeto de estudio de la antropología y la sociología. El conjunto de artículos y entrevistas que reúne este trabajo ofrece al lector interesado temas en los que el Grupo de Investigación en Antropología y Sociología de las Emociones (GREM) —establecido en 1994, bajo la coordinación del autor, en la UFPB- ha trabajado durante más de 20 años.

Publicado en Brasil por Appris, este trabajo se divide en 16 capítulos, precedidos por un breve prefacio y una introducción. Todos los capítulos han sido debatidos en congresos académicos, publicados en 
revistas especializadas o fueron la base para la composición de materiales de periódicos nacionales. Por lo tanto, es una obra que expresa el camino teórico y metodológico desarrollado por Koury como coordinador del GREM y editor de la Revista Brasileña de Sociología de la Emoción, fundada en 2002. Entre otras iniciativas institucionales pioneras, se destaca su participación regular como coordinador del grupo de trabajo en antropología y sociología de las emociones en las principales reuniones científicas, como la Reunión Brasileña de Antropología (RBA), la Reunión de Antropología del Norte y Noreste (ABANNE), la Reunión Ecuatorial de Antropología (REA) y el Congreso de la Asociación Latinoamericana de Sociología (ALAS).

Como parte de la investigación para el desarrollo de estos campos de estudio, desde 1990, la extensa obra de Koury presenta y discute las implicaciones metodológicas de la investigación de las emociones. De esta manera, como profesor, editor y participante en eventos académicos en Brasil y en Latinoamérica, Koury tiene un significado histórico para la consolidación de estos campos de estudio en el país. Otras formas de colaboración para la institucionalización de estos campos, en Brasil, han sido las traducciones y publicaciones de textos de autores como Marcel Mauss (2004; 2009), Georg Simmel (2002; 2003; 2010a; 2010b) y Gabriel Tarde (2003; 2004; 2005a; 2005b), entre otros, que tienen como objetivo situar al lector interesado en la discusión teórica y metodológica en el lugar de las emociones como objeto de estudio de las ciencias sociales.

Dicho esto, desde una perspectiva teórica del interaccionismo simbólico, los 16 artículos que estructuran el libro desarrollan un análisis social para destacar las tensiones relacionales entre emociones, cultura y sociedad, en una sociedad compleja, en particular la modernidad brasileña y occidental. Para ello, Koury coloca la emoción como categoría analítica central y discute la densa red de significados, en el sentido desarrollado por el antropólogo
Clifford Geertz (1989), que modula el problema de los modos y estilos de vida emergentes y la individualidad. Heterogénea y compleja, esta red de significados, a su vez, conduce al autor al estudio de los componentes de cohesión y pertenencia, consolidación y fragmentación, así como a las tensiones interiores y las fronteras que marcan el proceso de constitución del individuo y de la individualidad.

Con esta propuesta de análisis, Koury profundiza en el concepto de intersubjetividad y ofrece medios interpretativos para la comprensión de la interrelación entre las culturas objetivas y subjetivas organizadas en un proceso de interacción social. Esto, a su vez, le permite problematizar las configuraciones sociales que modulan las expresiones individuales de las emociones. En su trabajo, se hace una crítica incisiva a los análisis de las perspectivas que tienen una orientación social lineal y estructural, las cuales relegaron a un segundo plano, en la visión del autor, el proceso continuo de formación de la subjetividad como fenómeno antropológico y sociológico.

Pero, finalmente, ¿qué son la sociología y la antropología de las emociones? ¿Cuál podría ser el objeto de estas disciplinas? ¿Cuáles son las preocupaciones que permean las discusiones dentro de estos campos disciplinarios? Como uno de los autores importantes en la aparición de estos campos disciplinarios en la academia brasileña, Koury (2004; 2009) sitúa a la sociología y la antropología de las emociones como líneas analíticas recientes, pero en creciente expansión en todo el país y conectadas por el mismo proceso de institucionalización. Por lo tanto, basado en experiencias de investigaciones realizadas durante más de 20 años, moviliza diferentes cuadros teóricos y ofrece una clave para entender los puntos ahora subrayados, y construye una sólida definición de emoción como objeto de estudio de la antropología y sociología:

Las emociones en las ciencias sociales y, específicamente, en la antropología y la sociología, pueden 
definirse como una red de sentimientos orientados directamente a los demás, causados por la interacción con los otros en un contexto y situación social y cultural determinados. La antropología y la sociología de las emociones, consideradas áreas de interés en intenso intercambio y debate, suponen, de esa forma, que las experiencias emocionales singulares, sentidas y experimentadas por una persona, son producto de la relación entre los individuos, la cultura y la sociedad de la que se es parte. En sus fundamentos analíticos van más allá de lo que siente una persona en particular en determinadas circunstancias o en relación con las historias de vida estrictamente personales. Las preocupaciones que guían los debates dentro de estas disciplinas que relacionan emociones, cultura y sociedad, por lo tanto, se ocupan de los factores culturales y sociales que influyen en la esfera emocional, cómo interactúan, cómo se conforman y hasta donde llega la influencia y reciprocidad entre ellos (p. 9).

A partir de estos supuestos planteados por Koury, ¿qué leer en sociología y antropología de las emociones? Esta colección ofrece una amplia gama de temas que pueden concebirse como objetos de la antropología y la sociología de las emociones. Este libro tiene como telón de fondo los modos y estilos de vida emergentes, en particular el problema de la individualidad en la modernidad occidental y en Brasil. Se tratan temas relacionados con la antropología y la sociología de las emociones, como amistad, miedo, coraje, añoranza, envejecimiento, amor, entre otros, todos analizados como interacciones tensas que se manifiestan con gran intensidad, envueltas en procesos siempre delicados de modos y estilos de vida en la contemporaneidad.

En este marco conceptual, el tema de la amistad tiene una centralidad analítica única, pues ocupa cinco de los 16 capítulos del libro. En este sentido, Koury presenta inicialmente un resumen del concepto de amistad, en específico en el mundo occidental y contemporáneo brasileño. Para el autor, la amistad puede analizarse como un concepto relacional que implica lealtad, fidelidad, confianza y confidencialidad. Sin embargo, la amistad como una relación personal que permite revelar los secretos más íntimos a otros, implica también la noción de traición. Así, en una relación de amistad, la confiabilidad debe ser negociada y renegociada en cada nueva interacción relacional. Así, la acción voluntaria de mantener lazos de amistad basados en códigos de ética y moral fortalecen las reglas de la confianza mutua entre las partes involucradas.

En este sentido, el autor incorpora los análisis del aspecto ético de la amistad. En la medida en que estudia el proceso de solidaridad y conflicto que marca la experiencia de la amistad en la adultez, Koury intenta comprender, sin embargo, cómo se experimenta en general el camino egoico en esta etapa generacional. Así, al analizar la lógica de diferenciación y conflicto que integra un proyecto personal y la búsqueda de un reconocimiento profesional, señala que las relaciones de amistad en la edad adulta están rodeadas por la razón lógica del mercado. De esta manera, el comportamiento emocional se experimenta como una acción individual.

Para seguir con su argumento, señala que la amistad puede ser vista como un principio rector de la social y la cultura. Así, las relaciones pueden ser experimentadas tanto en la forma de la sociabilidad más simple como en la más compleja. Se analiza la relación entre los conceptos de amistad y sociabilidad, como también el proceso de elección y negociación permanente que conlleva la aventura de tener amigos. La experiencia de tener amigos implica una relación ambivalente. Por un lado, el descubrimiento de la diferencia y el encuentro con el otro; por el otro, miedo o rechazo de este encuentro. Estos dos aspectos, a su vez, permiten la construcción de formas de convivencia y búsqueda 
de entendimiento mutuo. Como una experiencia relacional, la amistad actúa como una base para una forma de sociabilidad más amplia; sin embargo, la experiencia cultural de amistad implica un proceso permanente de negociación y vigilancia, así como una búsqueda de la conformidad con las normas y códigos de ética establecidos.

Koury también analiza la "amistad difícil", es decir, la tendencia a mantener amistades y sus ambigüedades en un sistema individualista. Destaca el carácter relacional del concepto de amistad, así como la noción de confianza mutua que tiene el vínculo de la amistad. Resalta la posibilidad de la traición que impregna este compromiso personal. En su análisis, y debido a la creciente urbanización, el individualismo y la competencia, revisa los códigos de amistad que interfieren en las relaciones de confianza que implican las redes de amigos, y señala que mantener una amistad requiere esfuerzos significativos, como la renegociación de los códigos que orientan este bono y su monitoreo permanente.

Con base en esto, Koury investiga "lo que significa ser un amigo", y con este objetivo, analiza los significados de la forma de ser y tener un amigo, y lo que podría llamarse amigo. El autor llega a la conclusión de que un amigo puede definirse como un otro relacional con quien se comparten experiencias, lo que implica una relación de confianza. Esta acción de compartir valores, experiencias y proyectos es lo que define a un amigo. Sin embargo, con el proceso de crecimiento de la individualidad, se ha intensificado el temor a ser traicionado. En el proceso de construcción de amistad, las personas necesitan enfrentarse todos los días con la extrañeza y la dificultad personal de entrega de uno a otro.

En los capítulos que siguen, Koury presenta análisis pertinentes de la cultura del miedo. Para ello, mira cómo el temor al extranjero, en el Brasil contemporáneo, ha provocado una creciente necesidad de seguridad personal y privada. La cultura del miedo ha hecho posible una construcción invisible que amplía la distancia entre las personas. Para Koury, el miedo a la violencia ha afectado principalmente a los jóvenes, como una forma de expresión y estilo de vida. El autor analiza el temor de la población a la violencia. Define que este miedo se debe al proceso creciente de individualidad que ha caracterizado a las grandes ciudades, así como el uso de instrumentos de seguridad personal y privada, y la visión de la fragilidad de la población hacia las instituciones. Al final, menciona la gran desigualdad social que vive el país. Antes de esta declaración, reflexiona sobre los conceptos de miedos y temores comunes como aspectos centrales para comprender a una sociedad determinada. Koury relaciona emociones, temores y sociabilidad para colocar temores y miedos comunes como las emociones que implican tensión, ambivalencia, conflicto de orden y desorden en un espacio social particular.

Es importante tener en cuenta que en las listas de definición conceptual de Koury el miedo presenta varias expresiones del ethos y la cosmovisión de cada individuo relacional, por lo que impregna toda la cultura emocional de una sociabilidad determinada. En este sentido, la experiencia relacional del miedo no puede concebirse sólo como un gesto de retirada; por el contrario, sentir miedo señala también el aspecto de acción de ese sentimiento. El miedo abre nuevos caminos para que el individuo recree otras posibilidades de vivir sus experiencias cotidianas.

Todos los capítulos del libro ponen de relieve la importancia de las emociones para la comprensión de la relación entre individuo y sociedad frente a las ciencias sociales, en especial la antropología y la sociología. Vislumbra el tema del individuo en la sociedad occidental y brasileña contemporánea desde la perspectiva de la relación siempre tensa y continuamente situada en los frágiles vínculos entre las emociones, la cultura y la sociedad. En este importante trabajo, las relaciones entre individuo, cultura 
y sociedad aparecen en todos los capítulos, en sus formulaciones tensas, ambiguas y ambivalentes; en la vida diaria, hacen redes, se edifican uno al otro de manera intermitente, conflictiva y continua. Este trabajo es una lectura obligada para profesionales y estudiantes de las ciencias sociales, con énfasis especial en la antropología y la sociología, así como la filosofía, la psicología y el psicoanálisis. D

\section{Bibliografía}

Durkheim, Émile, 2002, "Filosofia do dinheiro: resenha”, en Revista Brasileira de Sociologia da Emoção, vol. 1, núm. 2, pp. 242-245.

Geertz, Clifford, 1989, A interpretação das culturas, Livros Técnicos e Científicos, Río de Janeiro.

Koury, Mauro Guilherme Pinheiro, 2004, Introdução à sociologia da emoção, Manufatura, João Pessoa.

— 2009, Emoções, cultura e sociedade, cRV, Curitiba.

Mauss, Marcel, 2004, "A coesão social nas sociedades polisegmentárias", en Revista Brasileira de Sociologia da Emoção, vol. 3, núm. 7, pp. 145-160.

—_, 2009, "A oração. Introdução geral”, en Revista Brasileira de Sociologia da Emoção, vol. 8, núm. 24, pp. 754-768.

Simmel, Georg, 2002, "A carta: por uma sociologia do segredo”, en Revista Brasileira de Sociologia da Emoção, vol. 1, núm. 3, pp. $384-387$.

—_, 2003, "Fidelidade: uma tentativa de análise sócio-psicológica”, en Revista Brasileira de Sociologia da Emoção, vol. 2, núm. 6, pp. 513-519.

, 2010b, “Um passeio sobre a questão da fronteira social”, en Revista Brasileira de Sociologia da Emoção, vol. 9, núm. 25, pp. 370-379.

, 2010a, “Gratidão: um experimento sociológico”, en Revista Brasileira de Sociologia da Emoção, vol. 9, núm. 26, pp. 819-835.

Tarde, Gabriel, 2003, “A oposição e a adaptação”, en Revista Brasileira de Sociologia da Emoção, vol. 2, núm. 4, pp. 151-167.

__ 2004, "As leis sociais. Esboço de uma sociologia. Parte l”, en Revista Brasileira de Sociologia da Emoção, vol. 3, núm. 9, pp. 414-438.

__. 2005a, "As leis sociais. Esboço de uma Sociologia. Parte II”, en Revista Brasileira de Sociologia da Emoção, vol. 4, núm. 10, pp. 91-116.

__ 2005b, "As leis sociais. Esboço de uma Sociologia. Parte III", en Revista Brasileira de Sociologia da Emoção, vol. 4, núm. 11, pp. 223-247. 